\title{
Multiple-schedule interactions and discrimination
}

\author{
DAVID W. ROWE and JOHN C. MALONE, JR. \\ University of Tennessee, Knoxville, Tennessee 37916
}

\begin{abstract}
Pigeons received variable-interval (VI) reinforcement for keypecking during randomized presentations of seven line-orientation stimuli forming a continuum ranging from horizontal ( $0 \mathrm{deg})$ to vertical $(90 \mathrm{deg})$. Each line presentation lasted for $30 \mathrm{sec}$ and was preceded and followed by 30 -sec time-outs. After responding stabilized, only responding in the two extreme stimuli 10 and $90 \mathrm{deg}$ ) was reinforced. As discrimination training proceeded, strong behavioral contrast and dimensional contrast effects appeared. However, only marginal local effects (local contrast and local dimensional effects), exerted by one line-orientation component upon a second, appeared, indicating that behavioral and dimensional contrast may be independent of parallel local effects. An attempt was made to apply Blough's (1975) quantitative model of operant generalization and discrimination to the present discrimination procedure. However, this model did not predict the generalization gradient shape that was experimentally obtained. This experiment also yielded two serendipitous findings: (1) Positive behavioral contrast appeared in an extinctionrelated stimulus (time-out) when other stimuli were switched from reinforcement to extinction (hitherto, positive behavioral contrast had been observed only in responding to a reinforcementrelated stimulus when other stimuli were switched from reinforcement to extinction), and (2) final responding was higher in the presence of an extinction stimulus that had always been an extinction stimulus than it was in the presence of other extinction stimuli that had previously been paired with VI reinforcement.
\end{abstract}

At one time, it appeared that performance during the various components of a multiple schedule were independent (cf. Ferster \& Skinner, 1957). This belief, coupled with the fact that discriminations are readily demonstrated with this type of schedule, made it reasonable to argue that discrimination formation need not be accompanied by interactions among components. However, during the past two decades, it has become clear that a number of interactions among the multiple schedule's components do occur, and that these interactions usually accompany the development of a discrimination. In fact, it has been suggested (Malone $\&$ Rowe, in press) that such interactions may determine the outcome of discrimination training. Therefore, interest in the detailed analysis of these interactions is warranted.

At least six types of interactions have been described. These six types can be divided logically into two major categories: (1) local effects, and (2) overall effects.

\section{Local Interaction Effects}

The two major classes of interaction effects differ according to the nature of the data that demonstrate their presence. Local effects, as defined here, are shown when response rates during various presenta-

Reprints may be obtained from David W. Rowe, Department of Psychology, University of Tennessee, Knoxville, Tennessee 37916. tions of a stimulus (i.e., components) systematically vary as a function of a specific preceding stimulus. For example, in a situation involving two stimuli (A and $B$ ), there exist two local response rates for $\mathbf{A}$ : (1) the rate associated with occurrences of $A$ when it immediately followed an occurrence of $A$, and (2) the rate associated with $A$ when it immediately followed B. If response rates are consistently higher (or lower) for one average local response rate than for others, we call this a local interaction effect, because response rates during individual presentations of $\mathrm{A}$ vary as a function of the specific stimulus immediately preceding it.

There are three specific types of local interaction effects. These are local induction, local contrast, and local dimensional effects. The term "induction," as interpreted by Skinner (1938), refers to a convergence of two response rates that are correlated with stimuli signaling different rates of reinforcement. Specifically, local induction refers to a change in the response rate correlated with a specific stimulus (relative to that stimulus' overall average) in the direction toward the rate associated with the preceding component. For example, assume that Stimulus A, an Sis associated with nonreinforcement and with low overall rates of response, whereas Stimulus B, an $\mathrm{S}+$, is associated with reinforcement and with high overall rates of response. If local response rates for A following B are consistently higher than those for A following itself, this is induction, because the rate 
in $\mathbf{A}$ rises above its average and toward the average rate in $B$. Likewise, local induction is present when local response rates for $\mathbf{B}$ following $\mathbf{A}$ are consistently lower than those for B following itself, because the response rate in $B$ falls below its average and toward the average in A. Local induction is an interaction effect that is commonly found in discrimination studies only at the outset of discrimination training and after the discrimination is very well learned (cf. Malone, 1976; Malone \& Rowe, in press; Pavlov, 1927-although none of these authors called their effects by this name).

Opposed to local induction is the interaction effect labeled local contrast by Malone and Staddon (1973). Local contrast refers to a change in the response rate associated with a specific stimulus (relative to that stimulus' overall average) in the direction opposite to the rate associated with the preceding component. Thus, applied to the above example, local contrast describes the situation in which the local response rates in $\mathbf{A}$ (the $\mathbf{S}-$ ) following $\mathbf{B}$ (the $\mathbf{S}+$ ) are consistently lower than those in A following itself, and the situation in which local response rates in B following A are consistently higher than they are in B following itself.

Local contrast appears at the time a discrimination begins to develop (i.e., overall response rates diverge) and usually persists until the discrimination is well learned (i.e., response rates stabilized). It then fades away as local induction replaces it. (For some pertinent research, see Boneau \& Axelrod, 1962; Malone, 1976; Malone \& Rowe, in press; Nevin \& Shettleworth, 1966; Pavlov, 1927.)

A third type of local interaction effect has recently been reported (Hinson \& Malone, 1980; Malone, 1976; Malone \& Rowe, in press), which can be called a local dimensional effect. This effect exists when local response rates in a specific stimulus vary as a function of the degree of similarity between that stimulus and whatever stimulus preceded it (e.g., their relative positions along a common stimulus dimension), even when the various preceding stimuli were associated with identical reinforcement schedules. To illustrate, first assume a three-stimulus (A, $B$, and $C$ ) discrimination situation in which $A$ is presented in extinction and $B$ and $C$ are presented with identical schedules of reinforcement that produce approximately the same rates of response. Also, assume that $\mathbf{A}$ lies closer to $B$ on the stimulus dimension than it does to $\mathrm{C}$. Local dimensional effects would exist if response rates to $A$ following $B$ were consistently higher (or lower) than to A following C.

Research indicates that local dimensional effects appear at the time discriminative responding begins to develop (Malone \& Rowe, in press). It should be noted that this is about the same time that local contrast appears. However, local dimensional effects tend to disappear before local contrast. When present, local dimensional effects often take the form of a "contrast." That is, as similarity between one stimulus and an immediately preceding stimulus associated with different reinforcement frequency increases, the difference between their local response rates increases.

\section{Overall Interaction Effects}

The overall interaction effects are defined as systematic variations in overall response rates in one component due to the presence of other components. An overall response rate is the rate associated with a given stimulus averaged across all of its presentations during an experimental session. It is, therefore, the average of all local response rates correlated with a specific stimulus. There are at least three types of overall interaction effects; these are induction, behavioral contrast, and dimensional contrast.

Overall induction refers to a change in responding in one stimulus as a result of, and in the same direction as, a change in responding in another stimulus. Thus, induction could describe the situation in which several similar stimuli are not originally associated with reinforcement, but subsequent responses to one are reinforced, and as a result, the response rates for all of the stimuli increase.

Behavioral contrast is an interaction effect that was first studied extensively by Reynolds (1961a, 1961b, 1961c) and by Reynolds and Catania (1961). This effect is opposite in direction to induction. That is, it involves a change in the response rate in one stimulus as a result of, and in a direction opposite to, a change in response rate in another stimulus. For example, Reynolds (1961b) reported that response rates in a variable-interval (VI) component increased when the reinforcement schedule in another component was shifted from VI reinforcement to extinction (EXT).

Behavioral contrast frequently accompanies successive discriminations, although Terrace (1963) showed that behavioral contrast may not accompany discriminations trained with his specific "learning without errors" procedure. When behavioral contrast does accompany successive discriminations, it first appears as the discrimination begins to develop, and it persists even after the discrimination is firmly established. Because of its relative permanence, behavioral contrast is occasionally referred to as a "sustained contrast" (e.g., Mackintosh, 1974) in order to distinguish it from local contrast, which is impermanent under some conditions (Malone, 1976) and therefore a "transient contrast."

Several researchers (Blough, 1975; Catania \& Gill, 1964; Farthing, 1974; Hinson \& Malone, 1980; Malone \& Rowe, in press) have reported the overall interaction effect that Blough (1975) has called "di- 
mensional contrast." This effect is observed in discrimination training situations that use components associated with a number of stimuli from a single stimulus dimension. For example, Catania and Gill (1964) used a vertical column of 16 lights as a stimulus continuum. Each of the top eight lights $(\mathrm{S}+$ ) was associated with fixed-interval reinforcement; each of the remaining eight lights $\left(\mathrm{S}^{-}\right)$was associated with extinction. This type of procedure often results in lower responding at $\mathrm{S}-$ values close to the $\mathrm{S}+$ set as compared with other $S-$ values somewhat farther removed from the $\mathrm{S}+$ set (negative dimensional contrast); also, it shows higher responding at $S+$ values close to the $\mathrm{S}$ - set as compared with other $\mathrm{S}+$ values somewhat farther removed from the $S$ - set (positive dimensional contrast). Following another procedure, in which the extreme values of a stimulus dimension are $S+s$ and all other values are $S-s$, negative dimensional contrast effects associated with each $\mathrm{S}+$ region may appear in a $\mathrm{W}$-shaped overall gradient (Hinson \& Malone, 1980; Malone \& Rowe, in press).

Dimensional contrast appears during the early stages of discrimination formation (Catania \& Gill, 1964; Hinson \& Malone, 1980) and fades away as training continues. However, dimensional contrast (and local contrast) can be restored by changing the sequence of stimuli or by making the stimuli less discriminable (Catania \& Gill, 1964; Malone, 1976).

Spence's (1937) model of discrimination and generalization has considerable difficulty accounting for dimensional contrast. Blough (1975) has noted this and, in reaction, has offered an alternative model. He has shown that his model effectively deals with some of these problematic data. One objective of the following experiment was to extend a thorough application of Blough's model to data obtained from an additional dimensional contrast situation.

\section{Overall and Local Effects}

Local contrast and behavioral contrast are usually produced by the same experimental manipulations, and, as indicated above, they tend to appear at about the same stages in discrimination training. These facts suggest that the changes in overall responding (i.e., behavioral contrast) may simply be the sum of parallel changes in local responding (i.e., local contrast). Along these lines, Mackintosh (1974) has speculated that the initial appearance of behavioral contrast depends upon the concurrent appearance of local contrast. The new overall response rates, which were produced by local contrast and which comprise behavioral contrast, then become "conditioned." Finally, the underlying local effects disappear, but the behavioral contrast effect persists because of the conditioning.

The research of Mackintosh, Little, and Lord (1972) provided a test of Mackintosh's position. This research showed that inserting long $(60-\mathrm{sec})$ time-outs between all stimulus presentations prevented local contrast from appearing, and when this was done, behavioral contrast did not appear either. But when local effects were allowed to appear, behavioral contrast effects appeared also. Mackintosh et al. took these observations to mean that the appearance of behavioral contrast depends upon the occurrence of local contrast. Although not elaborated upon, Mackintosh et al.'s data also revealed that when both interaction effects occurred, the magnitude of the behavioral contrast effect was substantially greater than (more than double) the maximal local contrast effect. This suggests that behavioral contrast may be more than the sum of concurrent, or previously occurring, local contrast effects (cf. Malone \& Staddon, 1973). Therefore, it appears that interpretation of Mackintosh et al.'s results is difficult, and that more data will be necessary to determine whether or not behavioral contrast is an epiphenomenon. The experiment below provides some of this additional information.

In designing the present experiment, we assumed that 30 -sec time-outs placed between all stimulus presentations would be sufficient to eliminate local effects. Consequently, these were added to a successive discrimination that would ordinarily be expected to produce both behavioral contrast and local contrast. If local contrast were indeed eliminated, and if it is essential for the production of behavioral contrast, then neither should appear in this experiment. But, if behavioral contrast is independent of local contrast, then it should appear even without local contrast. Finally, if local contrast is not eliminated, then behavioral contrast's independence can still be indicated by a behavioral contrast effect considerably larger than the effects on overall response rates produced by the local effects.

Along similar lines, dimensional contrast often appears in conjunction with local contrast and local dimensional effects (Malone \& Rowe, in press). In addition, these interactions (particularly local contrast and dimensional contrast) tend to disappear under similar conditions and tend to be restored by the same methods. These observations suggest that dimensional contrast may also be determined by local effects. The third purpose of this experiment was to test this possibility; this, too, can be done by inserting time-outs to remove local effects.

In this experiment, seven stimuli from a common stimulus dimension (a line tilt continuum) were presented in pseudorandom order. The stimulus at each extreme of the continuum was associated with reinforcement, whereas the five other stimuli were associated with extinction. It has previously been reported (Hinson \& Malone, 1980; Malone \& Rowe, in press) that the dimensional contrast effect produced by this procedure (without time-outs) appears in the 
form of a W-shaped overall gradient. This gradient, which is a maintained generalization gradient (cf. Rilling, 1977), is extremely stable from one day to another. If local effects are prevented in the present experiment by the insertion of time-outs, and if dimensional contrast depends upon local effects, then dimensional contrast will also be prevented from appearing. If so, responding in an $\mathrm{S}-$ that lies close on the continuum to an $\mathrm{S}+$ would not be lower than responding in other $S-S$ that are more distant from the $S+$. As a result, the overall gradient could not be $\mathrm{W}$-shaped, but would instead be U-shaped or possibly V-shaped. Therefore, in the following experiment, U-shaped (or V-shaped) gradients will indicate that dimensional contrast is dependent upon local effects. But the occurrence of W-shaped gradients (when local effects have been eliminated) will indicate that dimensional contrast is independent of local effects.

\section{Method}

\section{Subjects}

Three Silver King (Birds 53, 81, and 83) and two White Carneaux (Birds 62 and 55) pigeons were maintained at approximately $80 \%$ of their free-feeding weights. All of the birds had a long and varied experimental history. However, only two birds had had any previous exposure to line-orientation discriminations; this exposure ended about 4 years prior to the present experiment.

\section{Apparatus}

The experimental chamber was $41.5 \times 34.5 \times 38 \mathrm{~cm}$. The box was constructed of wood and Plexiglas and opened from the top. A 1.12-W houselight, which was situated in the center of the top panel, provided illumination throughout most of the experimental session. The houselight was extinguished during reinforcement ( $3 \mathrm{sec}$ access to mixed grain). Located on one wall, $6.5 \mathrm{~cm}$ above the floor, was a $5.5 \times 5.5 \mathrm{~cm}$ food aperture. Immediately above the food hopper was a 6-W light, which illuminated the feeder area during reinforcement deliveries. A transparent response key was fixed $12 \mathrm{~cm}$ above the top of the food aperture and $24 \mathrm{~cm}$ above the floor. A force of approximately $.3 \mathrm{~N}$ was required to depress the key. A 6.3-V Grason-Stadler stimulus projector (equipped with 1.6-W bulbs), mounted behind the key, displayed line-orientation stimuli. Each of these stimuli consisted of a black bar on a white background. To eliminate extraneous noise, the operant chamber was enclosed in a soundproofed box. Also, a ventilation fan and a Gerbrands white noise generator operated throughout the experimental session. All programming and recording equipment was housed in an adjacent room.

\section{Procedure}

Seven line-orientation stimuli [0 (horizontal), 15, 30, 45, 60, 75, and $90 \mathrm{deg}$ (vertical)] were back-projected onto the transparent response key during 30-sec components. A 30-sec no-stimulus period, or time-out, followed each line-orientation presentation. During the time-out period, the houselight remained on, the response key was unlit, and reinforcement was never delivered. In all, there were 98 time-out periods within each experimental session. Line orientations appeared in a pseudorandom order, with each one being presented 14 times [except for the stimulus $(0 \mathrm{deg})$ that began and ended the session, and was thus presented 15 times during the experimental session]. Each stimulus followed every possible stimulus equally often (twice).

The experiment consisted of two conditions. In the first condition (VI/ALL), responses associated with any of the line orienta- tions were reinforced according to a variable-interval (VI) 30-sec schedule. Once all of the birds were responding at a relatively stable rate (after 21 days), conditions were changed. The second condition (VI/EXT) was identical to the first, except that only responses associated with 0 and $90 \mathrm{deg}($ the $S+s$ ) were reinforced. Responses correlated with $15,30,45,60$, and $75 \mathrm{deg}$ (the $S-s$ ) no longer led to reinforcement. The VI/EXT condition continued for approximately 50 sessions.

\section{RESULTS}

\section{Dimensional Contrast and Local Effects}

Maintained generalization gradients for Days 1-3, $4-6,10,15,20,30$, and 40 of the VI/EXT condition are shown in Figure 1. These gradients represent the pigeons' average response rates as a function of line orientation. The group average (which is shown) is representative of the data for the individual birds (which are not shown here).

During the first day of VI/EXT, the group's overall gradient was relatively flat. By Day 2 , however, a W-shaped gradient appeared in spite of the 30 -sec time-outs. Between Days 3 and 6, the gradients became progressively sharper and the $\mathrm{W}$-shape became more obvious. The $\mathrm{W}$-shaped gradients persisted throughout the VI/EXT condition; however, it appeared that the form was gradually becoming a Ushape at the condition's end. Dimensional contrast shoulders thus appeared throughout the VI/EXT condition.

Further analysis showed that response rates in 30 and $60 \mathrm{deg}$ declined faster than was true of the other extinction stimuli. In particular, responding during these stimuli showed major declines on Days 2 and 3 , while responding during 15,45 , and $75 \mathrm{deg}$ remained relatively unchanged. From Day 4 on, however, response rates in 15,45 , and 75 deg gradually decreased to levels close to (but still above) 30 and $60 \mathrm{deg}$. Of the five $\mathrm{S}-\mathrm{s}$, responding was usually highest during $45 \mathrm{deg}$. It was this relatively high response rate in 45 deg that primarily accounted for the W-shaped appearance of the maintained gradient after the first few sessions. Furthermore, it was the slow but continuous decline in the response rates associated with 45 deg from Day 20 to Day 40 that accounted for the apparent trend toward a $U$-shaped gradient.

While response rates in each $S$ - declined over the first few days of VI/EXT, response rates to each $\mathrm{S}+$ (i.e., 0 and $90 \mathrm{deg}$ ) increased. From Day 1 to Day 4, responding in 0 and 90 deg increased by about 70 responses/min. This large increase in responding illustrates positive behavioral contrast. After Day 15, response rates during 0 and $90-\mathrm{deg}$ presentations remained steady.

Figures 2 and 3 and Table 1 allow an assessment of the effect that the 30-sec time-outs had in eliminating local effects among line-orientation stimuli. In particular, Figure 2 shows the effect that each line- 


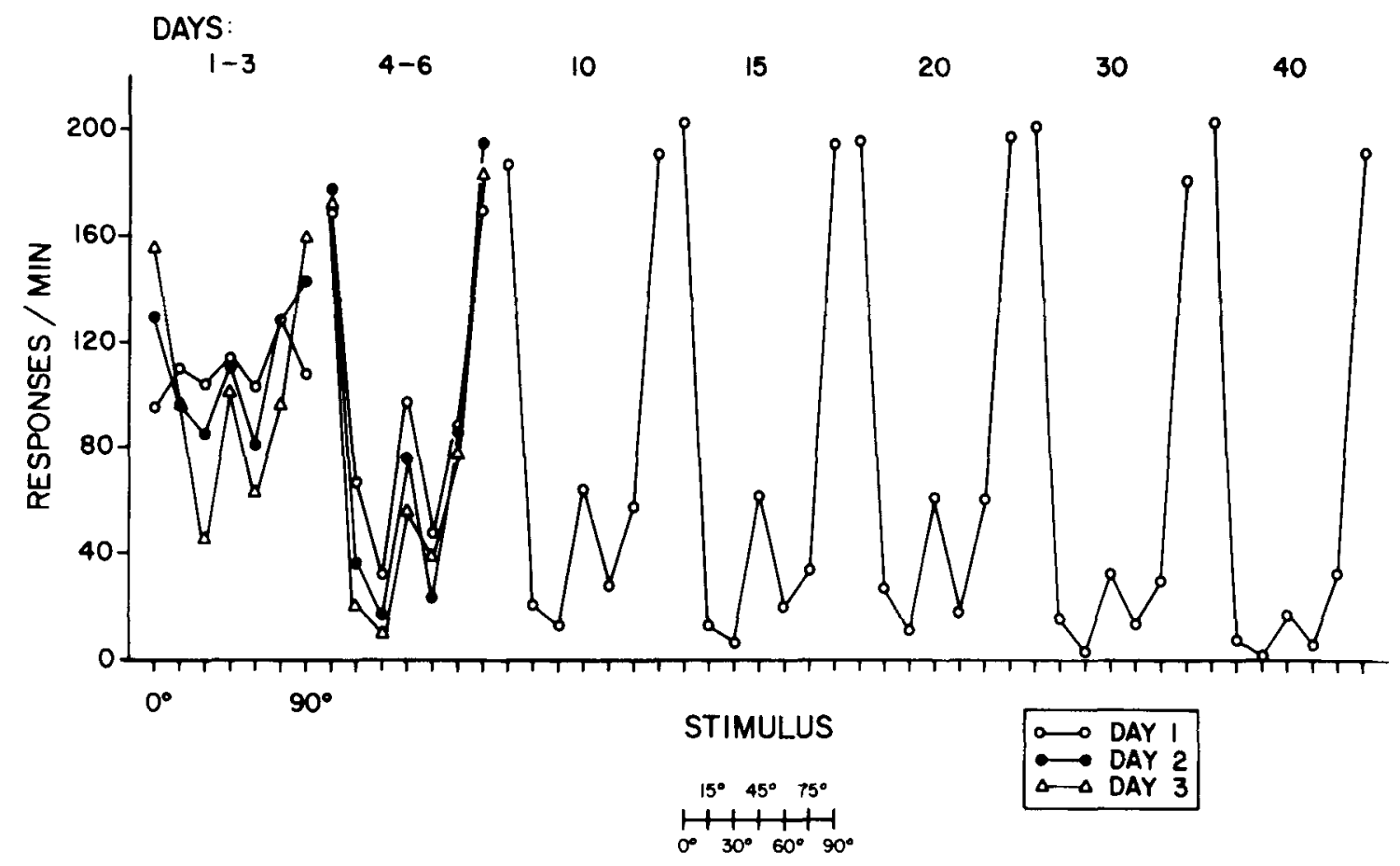

Figure 1. Maintained generalization gradients averaged across the five birds for each of the specified VI/EXT days. When three gradients appear in a single panel, the first of the 3 days is represented by unfilled circles, the second by filled circles, and the third by triangles.

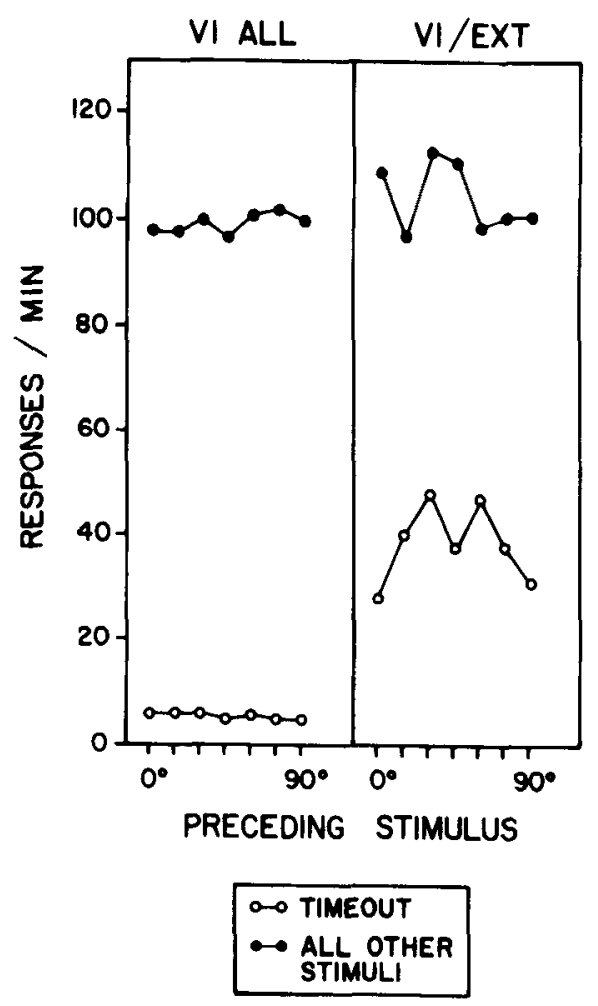

Figure 2. The five birds' average responding in time-out and line-orientation components when preceded by the indicated stimulus. The left panel shows data from the last day of VI/ALL; the right panel shows data from the first 2 days that each bird showed W-shaped maintained generalization gradients. See text for details. orientation stimulus had on responding during the two $30-\mathrm{sec}$ intervals that followed it. The first of these intervals was the 30 -sec time-out period; response rates, averaged across birds, during time-outs are indicated by the unfilled circles in Figure 2. These same rates are also listed in the TO (time-out) column of the "Average of Five Birds" portion of Table 1. The second interval was a 30-sec presentation of some lineorientation stimulus. In Figure 2, response rates associated with all following line-orientation stimuli are averaged together; these rates are represented by the filled circles in Figure 2, and they appear in the Mean column in the "Average of Five Birds" portion of Table 1. The left panel of Figure 2 displays responding during the last day of the VI/ALL condition, and the right panel shows average responding for the first 2 days of VI/EXT, during which individual birds showed a W-shaped overall gradient. These 2 days were: Days 4-5 for Bird 62; Days 3-4 for Birds 53, 83, and 55; and Days 2-3 for Bird 81. These particular days were chosen because we were most interested in the role local effects might play in the initial appearance of dimensional and behavioral contrast. Since individual birds first showed this gradient form at different times, it was reasonable to use data from the first 2 days that each bird demonstrated such an overall gradient.

On the last day of the VI/ALL condition, neither responding during time-out nor responding during the line-orientation interval varied as a function of 
Table 1

Response Rate in Each Stimulus as a Function of the Preceding Line-Orientation Component (PLO)

\begin{tabular}{|c|c|c|c|c|c|c|c|c|c|}
\hline \multirow[b]{2}{*}{ PLO } & \multicolumn{8}{|c|}{ Stimulus } & \multirow[b]{2}{*}{ TO } \\
\hline & 0 & 15 & 30 & 45 & 60 & 75 & 90 & Mean & \\
\hline \multicolumn{10}{|c|}{ Bird 62 (Days 4 and 5) } \\
\hline 0 & 210 & 87 & 9 & 97 & 114 & 148 & 261 & & 26 \\
\hline 15 & 201 & 45 & 28 & 61 & 28 & 125 & 268 & & 53 \\
\hline 30 & 250 & 112 & 14 & 90 & 45 & 152 & 294 & & 56 \\
\hline 45 & 300 & 89 & 39 & 89 & 15 & 156 & 243 & & 48 \\
\hline 60 & 281 & 50 & 7 & 117 & 28 & 76 & 231 & & 52 \\
\hline 75 & 244 & 54 & 7 & 99 & 21 & 101 & 303 & & 46 \\
\hline 90 & 221 & 101 & 26 & 51 & 21 & 118 & 212 & & 25 \\
\hline \multicolumn{10}{|c|}{ Bird 53 (Days 3 and 4) } \\
\hline 0 & 95 & 34 & 33 & 65 & 45 & 71 & 89 & & 0 \\
\hline 15 & 115 & 36 & 33 & 78 & 49 & 69 & 98 & & 0 \\
\hline 30 & 106 & 53 & 34 & 101 & 39 & 67 & 82 & & 0 \\
\hline 45 & 118 & 59 & 58 & 83 & 24 & 76 & 75 & & 1 \\
\hline 60 & 109 & 49 & 8 & 72 & 53 & 37 & 93 & & 0 \\
\hline 75 & 112 & 41 & 8 & 77 & 29 & 35 & 115 & & 0 \\
\hline 90 & 95 & 53 & 38 & 54 & 24 & 49 & 91 & & 0 \\
\hline \multicolumn{10}{|c|}{ Bird 83 (Days 3 and 4) } \\
\hline 0 & 146 & 74 & 25 & 74 & 53 & 53 & 171 & & 40 \\
\hline 15 & 139 & 60 & 25 & 23 & 36 & 43 & 127 & & 52 \\
\hline 30 & 146 & 105 & 34 & 45 & 27 & 99 & 155 & & 61 \\
\hline 45 & 121 & 85 & 40 & 73 & 27 & 109 & 161 & & 52 \\
\hline 60 & 147 & 33 & 4 & 66 & 29 & 55 & 131 & & 62 \\
\hline 75 & 151 & 53 & 23 & 65 & 41 & 27 & 157 & & 53 \\
\hline 90 & 129 & 89 & 8 & 18 & 35 & 48 & 165 & & 41 \\
\hline \multicolumn{10}{|c|}{ Bird 55 (Days 3 and 4) } \\
\hline 0 & 329 & 139 & 85 & 191 & 173 & 193 & 255 & & 15 \\
\hline 15 & 290 & 146 & 99 & 220 & 107 & 146 & 268 & & 15 \\
\hline 30 & 318 & 203 & 97 & 285 & 91 & 157 & 333 & & 23 \\
\hline 45 & 321 & 190 & 129 & 164 & 98 & 178 & 262 & & 13 \\
\hline 60 & 308 & 201 & 85 & 262 & 81 & 159 & 282 & & 22 \\
\hline 75 & 305 & 189 & 83 & 222 & 85 & 190 & 267 & & 19 \\
\hline 90 & 316 & 186 & 94 & 272 & 77 & 175 & 336 & & 15 \\
\hline \multicolumn{10}{|c|}{ Bird 81 (Days 2 and 3) } \\
\hline 0 & 106 & 26 & 43 & 83 & 55 & 58 & 133 & & 62 \\
\hline 15 & 89 & 25 & 47 & 36 & 52 & 62 & 134 & & 81 \\
\hline 30 & 116 & 53 & 36 & 52 & 28 & 96 & 100 & & 102 \\
\hline 45 & 90 & 26 & 64 & 80 & 29 & 80 & 138 & & 76 \\
\hline 60 & 90 & 10 & 12 & 84 & 52 & 38 & 75 & & 97 \\
\hline 75 & 80 & 29 & 13 & 102 & 27 & 52 & 126 & & 71 \\
\hline 90 & 94 & 66 & 22 & 18 & 21 & 59 & 153 & & 74 \\
\hline \multicolumn{10}{|c|}{ Average of Five Birds } \\
\hline 0 & 177 & 72 & 39 & 102 & 88 & 105 & 182 & 109 & 29 \\
\hline 15 & 167 & 62 & 46 & 84 & 54 & 89 & 179 & 97 & 40 \\
\hline 30 & 187 & 105 & 43 & 115 & 46 & 114 & 193 & 115 & 48 \\
\hline 45 & 190 & 90 & 66 & 98 & 39 & 120 & 176 & 111 & 38 \\
\hline 60 & 187 & 69 & 23 & 120 & 49 & 73 & 162 & 98 & 47 \\
\hline 75 & 178 & 73 & 27 & 113 & 41 & 81 & 194 & 101 & 38 \\
\hline 90 & 171 & 99 & 38 & 83 & 36 & 90 & 191 & 101 & 31 \\
\hline
\end{tabular}

Note-These are the averages of the first 2 days that each bird showed a W-shaped overall gradient. Stimuli and PLOs are given in degrees.

the preceding line-orientation stimulus. This, of course, was expected, because all the line orientations were presented with a VI 30-sec schedule, and all were associated with roughly equivalent response rates.
However, during VI/EXT, response rates in timeout took on an M-shape when plotted as a function of the preceding line orientation. This showed the expected effects of local contrast. A relatively high average response rate in the presence of a given stimulus leads to lower than average responding during the following stimulus, while a relatively low response rate in the presence of a given stimulus leads to higher than average responding during the following stimulus (Malone \& Staddon, 1973). Thus, due to local contrast, the form of this time-out gradient was the inverse of the overall gradient.

If the line-orientation components were truly shielded by time-outs from local interaction effects, then responding during their presentation should not vary as a function of the preceding line orientations. As a result, the gradient would be flat. On the other hand, if the time-outs did not shield the line-orientation components, then responding during them should vary as a function of the preceding line orientations. Consequently, the gradient would be M-shaped like that obtained for responding during time-out. Figure 2 shows that neither is the case; the gradient was neither M-shaped nor flat. This suggests that, in spite of the time-outs, some local effects (perhaps local dimensional effects) may have persisted to influence, albeit weakly, responding during the line-orientation components. Figure 3 allows closer examination of this possibility.

Figure 3 shows two sets of eight generalization gradients. The lower set of gradients shows response rates obtained in the present experiment. The upper set shows response rates that were originally obtained in a previous experiment by Hinson and Malone (1980). That experiment was procedurally similar to the present one, except for one important difference: No time-outs were used to separate successive presentations of line orientations. Consequently, Figure 3 affords an opportunity to compare the magnitude and pattern of the local effects found here (using 30 -sec time-outs) with the magnitude and pattern of the local effects found when using no time-outs.

Within each set of gradients, the rightmost seven show response rates during the seven line orientations when they followed a specific line-orientation stimulus. Thus, both far-right gradients represent response rates in 0-, 15-, 30-, 45-, 60-, 75-, and 90-deg components when preceded by $90 \mathrm{deg}$ (with a 0 -sec or 30-sec time-out intervening, of course). The farleft gradient in each set (labeled "overall") is the average of the seven gradients to the right. The data for the lower panel of this figure were collected from the first 2 days during which each bird showed a Wshaped gradient, as in the right panel of Figure 2. The data shown in the upper panel were also collected during an early stage of discrimination formation (i.e., soon after response rates in $\mathrm{S}+$ and $\mathrm{S}$ - components began to diverge and soon after a $\mathrm{W}$-shaped 


\title{
PRECEDING STIMULUS
}

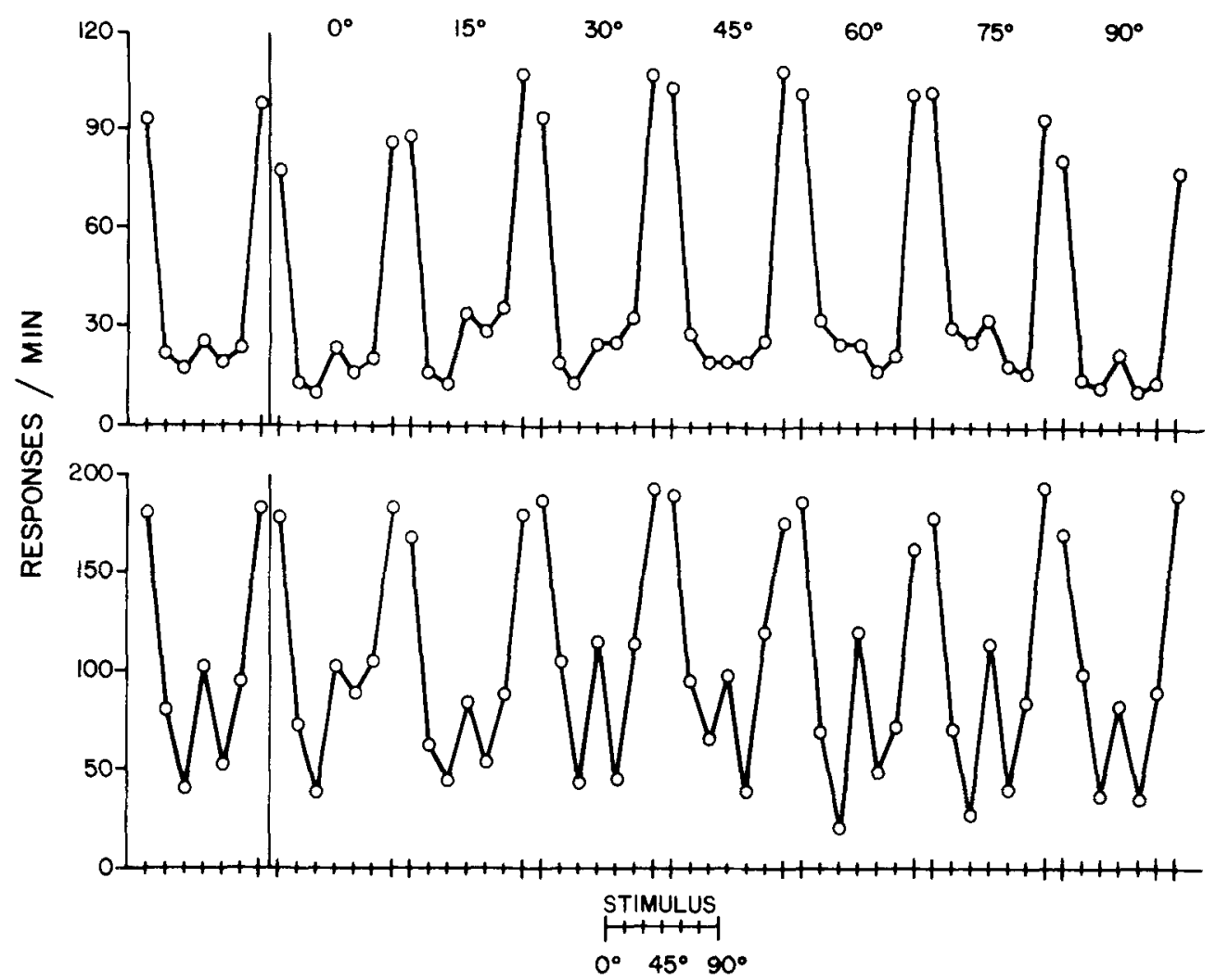

\begin{abstract}
Figure 3. The five birds' average responding in specific line orientations as a function of the preceding line orientation. The upper set of gradients shows data obtained using the present procedure without time-outs (adapted with permission from Hinson \& Malone, 1980); these gradients come from an early stage of discrimination formation. The lower set of gradients shows data from the present experiment that utilized 30-sec time-outs; these data were collected during the first 2 days that each bird showed a $W$-shaped overall maintained generalization gradient. The far-left panel in each gradient set shows the average of the data shown in the seven panels to its right.
\end{abstract}

overall gradient appeared). The data in both panels of the figure are across-subjects averages; individual data for the present experiment can be found in Table 1.

In the upper panel, response rates in components following the two stimuli associated with relatively high rates of response ( 0 and $90 \mathrm{deg})$ were lower than response rates in components following the stimuli associated with relatively low rates of response (15, $30,45,60$, and $75 \mathrm{deg}$ ). This showed that local contrast was present in the no-time-out study, because the rate of responding in a given component was inversely related to the rate prevailing in the preceding component. Stimulus similarity between one component and the preceding one also had a considerable effect upon local responding; that is, local dimensional effects also appeared in the experiment lacking time-outs. For example, when the preceding stimulus was 0,15 , or $30 \mathrm{deg}$, responding in similar stimulus components (such as 0,15 , and $30 \mathrm{deg}$ ) was lower than responding in less similar stimulus components (such as 60,75, and $90 \mathrm{deg}$ ). Likewise, when the pre- ceding stimulus was 60,75 , or $90 \mathrm{deg}$, responding in similar stimulus components $(60,75$, and $90 \mathrm{deg})$ was lower than responding in less similar stimulus components $(0,15$, and $30 \mathrm{deg})$. Thus, in addition to local contrast, local dimensional effects were also produced when using the present procedure without time-outs.

If the 30-sec time-outs used in the present experiment did not eliminate local effects (as intended), then the gradients in the lower panel should have resembled the gradients in the upper panel. However, if local effects were eliminated, then all of the gradients in the lower panel should have looked alike. And, if this were true, they would have closely resembled the W-shaped overall gradient. In general, the lower panel of Figure 3 shows that the latter was the case; most of the gradients resembled the W-shaped overall gradient, not the upper panel's gradients. However, the gradient showing all stimuli following 0 deg was an exception. For this gradient, response rates associated with stimuli distant from 0 deg were relatively high, whereas response rates associated with 
stimuli close to $0 \mathrm{deg}$ were relatively low. This pattern was consistently exhibited by individual birds; it occurred in 8 of 10 gradients obtained from the 5 birds for the selected 2 days. This result, of course, is somewhat similar to that shown in the upper panel (although, in detail, the lower 0-deg gradient was more like the upper 15-deg gradient than like the upper 0-deg gradient).

Even though, in the present experiment, there was a local dimensional effect on stimulus components following $0 \mathrm{deg}$, there was no local dimensional effect in stimulus components following any other stimulus. In the experiment using no time-outs, however, local dimensional effects were common to most of the stimuli, not just to $0 \mathrm{deg}$. This indicates that local dimensional effects were substantially reduced by the presence of 30-sec time-outs. In addition, local contrast was also reduced by the presence of time-outs. After all, both Figures 2 and 3 (lower panel) show that responding in components following 0 and $90 \mathrm{deg}$ was not consistently lower than responding in components following other stimuli. This, of course, contrasts with the no-time-out study, in which local contrast was observed. In sum, then, the $30-\mathrm{sec}$ timeout periods used in the present study did not completely eliminate local effects, but they did reduce them considerably.

\section{Behavioral Contrast and Local Effects}

As mentioned above, responding in the presence of 0 and $90 \mathrm{deg}$ showed positive behavioral contrast. This can be seen more clearly in Figure 4 . In this figure, response rates in these components are desig. nated by unfilled circles. During the first several days of VI/EXT (right panel of each graph), all of the birds responded at higher rates in the presence of 0 and $90 \mathrm{deg}$ than during the previous VI/ALL condition (left panel of each graph). Moreover, the average of the five birds shows that response rates rose from approximately $100 / \mathrm{min}$ during the last 7 days of VI/ALL to approximately $200 / \mathrm{min}$ by Days 5 to 15 of VI/EXT. In sum, the birds clearly showed positive behavioral contrast in these two stimuli.

The fact that a large positive behavioral contrast effect in these stimuli appeared indicates that positive behavioral contrast is not entirely produced by local contrast. This is because the condition change from VI/ALL to VI/EXT was accompanied by very weak local contrast effects (Figures 2 and 3). Thus, the large overall increase in responding associated with 0 and $90 \mathrm{deg}$ could not have simply been the sum of parallel local effects.

In the past, many researchers have observed (as we have here) that extinguishing responses associated with a stimulus that has previously signaled reinforcement (let us call this an $\mathbf{S}+/ \mathbf{S}-$ stimulus) leads to increased responding associated with a second $\mathrm{S}+$ that has remained as $\mathrm{S}+($ an $\mathrm{S}+/ \mathrm{S}+$ stimulus). It is possible that another aspect of positive behavioral contrast could consist of increased response rates associated with an $\mathrm{S}-$ that remains an $\mathrm{S}-$ (an $\mathrm{S}-/ \mathrm{S}-$ stimulus) when another stimulus is switched from an $\mathrm{S}+$ to an $\mathrm{S}-$. However, it appears that such an effect has not been previously reported. In the present experiment, time-out periods were signaled by a blank, dark key. These periods, which lasted for $30 \mathrm{sec}$ came after every line-orientation stimulus and were always associated with extinction. Since the blank key was correlated with extinction throughout the experiment, it can be considered an $\mathrm{S}-/ \mathrm{S}-$ stimulus. It is interesting to note that, in this experiment, responses in the presence of the $\mathrm{S}-/ \mathrm{S}-$ stimulus did increase when the change in conditions in the $S+/ S-$ stimuli was made. This positive behavioral contrast effect is illustrated in Figure 4.

During the last 7 days of the VI/ALL condition, the birds' responding in time-out (unfilled triangles) was relatively stable and low. Response rates in timeout then increased greatly for Birds 55, 83, 81, and 62 during the first few days of VI/EXT. (This increase would appear even more clearly in a figure in which smaller ordinate units were chosen; large ones were chosen here in order to accommodate the high response rates associated with the $\mathrm{S}+/ \mathrm{S}+$ stimuli). Rate of response then typically stabilized at this new elevated level. Bird 53 demonstrated the weakest positive behavioral contrast effect, but even this bird had higher response rates by Sessions 10 to 15 of the VI/EXT condition. Moreover, the birds' average time-out responding increased by a factor of 5 during the first 4 days of VI/EXT, reaching a plateau of approximately 50 responses $/ \mathrm{min}$. This pattern of response rate change and stabilization was parallel to that described above in the $S+/ S+$ components, and was similar to previous reports of positive behavioral contrast in S+/S+ components (Reynolds, 1961b).

In the VI/ALL condition, time-outs always followed S+ components. However, during VI/EXT, the likelihood that a time-out period would follow an $S+$ was only $2 / 7$, whereas $5 / 7$ of the time-out periods followed an $\mathrm{S}-$. Because of this difference between VI/ALL and VI/EXT, one would expect local contrast effects to differentially influence responding under the two conditions. Such a difference would produce higher time-out-related response rates during VI/EXT than during VI/ALL. Therefore, the overall increase in time-out responding (i.e., positive behavioral contrast) may have been due entirely to local contrast. If this were the case, it may be misleading to label this increase "positive behavioral contrast"; rather, it might be more precise and straightforward to refer to this as an "increase in overall response rates due to the introduction of positive local contrast."

A reexamination of Figure 2 will help resolve this issue. The unfilled circles represent response rates 


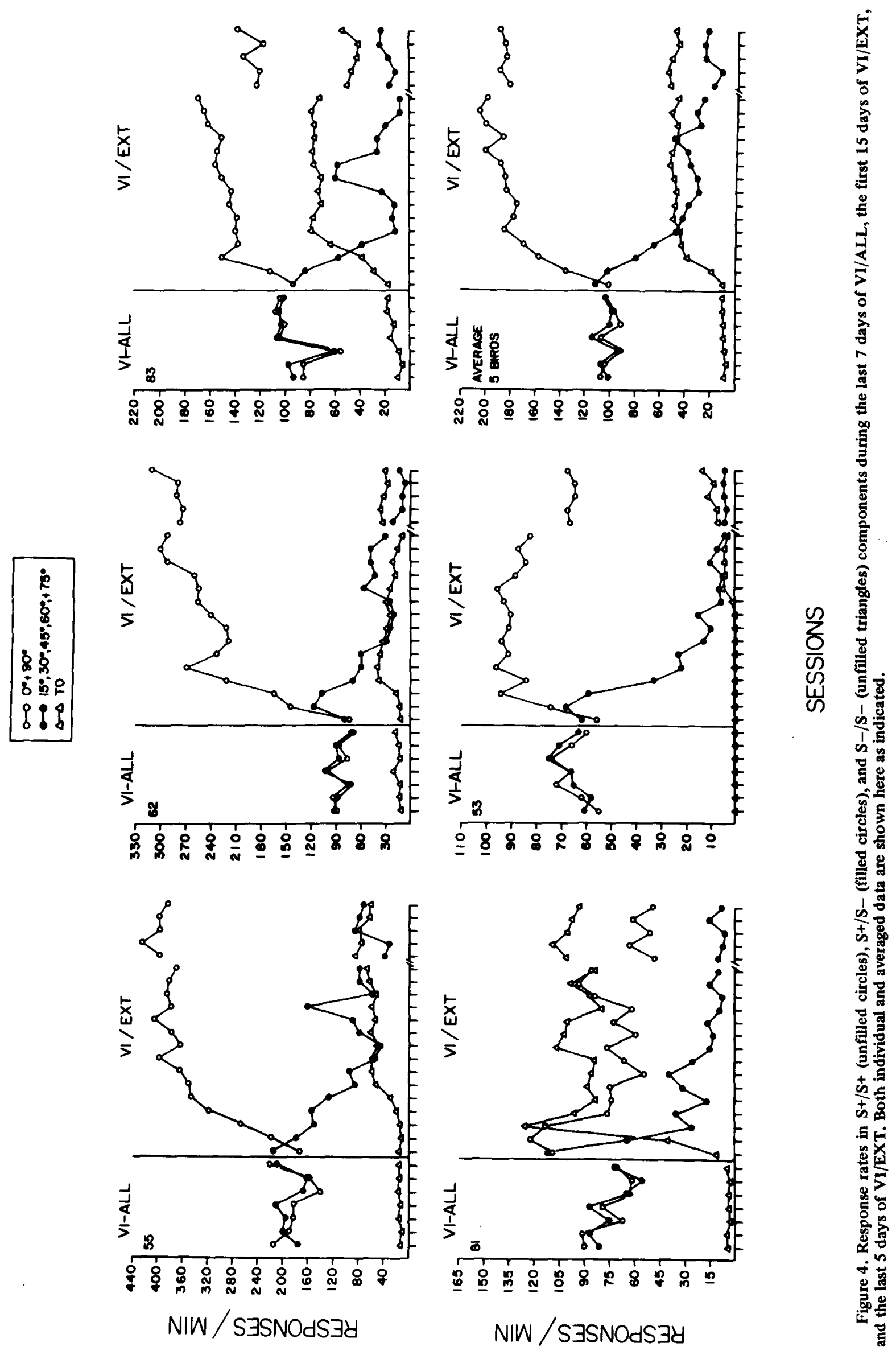


during particular time-out periods that immediately followed one of the seven line-orientation stimuli. The response rates averaged across the birds for the last day of VI/ALL appear in the left panel. These rates were low (about 5 response/min), and they showed no variation as a function of the particular preceding line orientation. However, the case was quite different for the data in the right panel (response rates averaged across birds for the first 2 days of $\mathrm{W}$ shaped overall gradients in the VI/EXT condition). Here, time-out-related responding did vary as a function of the particular preceding line-orientation. Specifically, response rates in time-outs that followed an $S-(15,30,45,60$, and $75 \mathrm{deg})$ were higher than those in time-outs that followed an $\mathrm{S}+(0$ and $90 \mathrm{deg})$. Thus, the introduction of S- stimuli produced positive local contrast in time-out and related increases in overall response rates.

The foregoing might seem to indicate that the appearance of positive behavioral contrast in the $S-/ S-$ stimulus can be attributed entirely to positive local contrast. That this was not the case is shown by response rates in time-out components that followed either 0 or 90 deg. These two sets of components are of special interest because they followed stimuli that were $\mathrm{S}+\mathrm{s}$ in both conditions. Therefore, they were equally influenced by local effects in both conditions, and, as a result, their associated response rates should have remained about the same from one condition to the next. But, Figure 2 shows that they were not about the same; response rates were much higher in the VI/EXT condition. This certainly cannot be easily accounted for in terms of local contrast. Hence, although positive local contrast contributed to the appearance of positive behavioral contrast in the S-/S- component, it did not solely determine it (cf. Malone, 1976).

Another interesting point concerning Figure 4 regards the relative response rates associated with the three types of stimuli at the end of the VI/EXT condition (i.e., the last 5 days of VI/EXT, which appear to the right of the break in the abscissa of each figure). First, one would expect that at the end of VI/EXT, the $\mathrm{S}+/ \mathrm{S}+$ stimuli (unfilled circles) would be correlated with the highest response rates, which was usually the case. (However, Bird 81 was an exception; this bird responded more rapidly during the $\mathrm{S}-/ \mathrm{S}-$ components!) Second, we might expect that response rates in the $\mathrm{S}+/ \mathrm{S}-$ stimuli would be slightly higher than those in the $S-/ S-$ stimulus, because the $S+/ S-$ stimuli were previously associated with reinforcement, whereas the $\mathrm{S}-/ \mathrm{S}-$ stimulus was not. The data show that the opposite was true. Four of the five birds showed consistently higher response rates in the $\mathrm{S}-/ \mathrm{S}-$ stimulus than in the $\mathrm{S}+/ \mathrm{S}-$ stimuli. Also, the average of the five birds showed that $S-/ S-$ responding was more than double $S+/ S-$ responding.
Only Bird 55, which showed no difference between $\mathrm{S}+/ \mathrm{S}-$ and $\mathrm{S}-/ \mathrm{S}-$, was an exception.

\section{DISCUSSION}

In the above experiment, 30-sec time-outs were inserted between all of the line-orientation components of a particular discrimination procedure. Ordinarily, this procedure would produce local contrast, local dimensional effects, behavioral contrast, and dimensional contrast. However, in this experiment, the 30-sec time-outs greatly weakened the local effects. Meanwhile, substantial behavioral and dimensional contrast effects appeared. Since the magnitudes of these overall effects considerably exceeded the magnitudes of the local effects, it may be concluded that behavioral and dimensional contrast were not wholly dependent upon local effects. Rather, behavioral contrast and dimensional contrast seem to be phenomena in their own right.

As noted previously, one purpose of the present study was to extend Blough's (1975) model of operant generalization and discrimination to the present procedure. Consequently, we used Blough's model in an attempt to simulate the pronounced W-shaped gradients that were obtained here. Although Blough's model was able to simulate some details of the actual data, even the simulation that best fit the actual data had two major failings. ${ }^{2}$ First, it did not show Wshaped gradients during the early stages of discrimination formation, as did the actual data. Rather, a W-shape appeared only after the discrimination was well developed. Second, even when a W-shape did appear, it was not pronounced. This was because response strength in $45 \mathrm{deg}$ was, at best, only slightly greater than response strength in 30 and $60 \mathrm{deg}$. On the other hand, the actual data showed response rates in 45 deg that were considerably higher than response rates in 30 and 60 deg. Hence, Blough's model could not produce dimensional contrast effects that appeared as early or as strongly as those obtained in the present study. These failings suggest that Blough's model needs modification if it is to account for the various dimensional contrast effects found in all types of discrimination situations.

In addition to the above findings, this experiment also yielded two unexpected, but consistent, findings. One of these concerned the relative response rates in $\mathrm{S}+/ \mathrm{S}-$ and $\mathrm{S}-/ \mathrm{S}-$ components. During the VI/EXT condition of this study, responding was greater in the $\mathrm{S}-/ \mathrm{S}-$ components than in the $\mathrm{S}+/ \mathrm{S}-$ components. This was surprising, because one would think that responding would be greater in the presence of an S- that historically had been associated with reinforcement than in the presence of an S- that had always been an $\mathrm{S}-$. Instead, it appears that some sort of "schedule contrast" effect occurred. That is, when 
the degree of reinforcement associated with a specific stimulus was altered, the organism tended to overadjust in its reaction to that stimulus. As a result, an $\mathrm{S}+$ that became an $\mathrm{S}$ - was responded to less frequently than an $\mathrm{S}-$ that had always been an $\mathrm{S}-$. If this analysis is appropriate, then it is reasonable to speculate that an organism will also overadjust to an $\mathrm{S}-/ \mathrm{S}+$ stimulus. This would lead to more frequent responding in $\mathrm{S}-/ \mathrm{S}+$ components than in $\mathrm{S}+/ \mathrm{S}+$ components. ${ }^{3}$ This, of course, is an issue for further experimentation. Another issue for further experimentation concerns the generality of the "schedule contrast" effect. For example, does the effect appear only when extradimensional stimuli are involved (such as time-outs and line orientations in the present study) or will it also appear when stimuli from a single dimension are used? Until such issues are explored, we can only conclude that the present finding is interesting but unusual.

The second serendipitous finding yielded by the present experiment was the appearance of positive behavioral contrast in the $\mathrm{S}-/ \mathrm{S}-$ stimulus (timeout). Although positive behavioral contrast in $\mathrm{S}+/ \mathrm{S}+$ responding has been reported many times in the past, it seems that positive behavioral contrast in S- $/ \mathrm{S}-$ responding has not been previously reported. Perhaps this is because most experiments dealing with behavioral contrast have employed only $\mathrm{S}+/ \mathrm{S}+$ and $\mathrm{S}+/ \mathrm{S}-$ stimuli. Obviously, behavioral contrast associated with $S-/ S-$ components could not be found in studies in which these components were not included. Furthermore, it is conceivable that only extradimensional $\mathrm{S}-/ \mathrm{S}-\mathrm{s}$ (such as time-out in this experiment) show behavioral contrast; these stimuli are usually excluded from behavioral contrast studies. Finally, even in cases in which behavioral contrast did occur in $\mathrm{S}-/ \mathrm{S}-$ components, the absolute response rates associated with these components may have been so low that relatively large increases went unnoticed. Whatever the case, the observation that $\mathrm{S}-/ \mathrm{S}-$ responding may show positive behavioral contrast has implications for several interpretations of behavioral contrast, such as "relative reinforcement theory" (Reynolds, 1961b), "additivity theory" (Gamzu \& Schwartz, 1973; Schwartz \& Gamzu, 1977), and "behavioral competition theory" (Hinson \& Staddon, 1978).

Reynolds (1961b) suggested that positive behavioral contrast results from an increase in the relative reinforcement frequency associated with the stimulus showing contrast. For example, assume that two stimuli (A and B) are originally associated with the same schedule of reinforcement. If responses in the presence of $\mathbf{A}$ are subsequently extinguished, then responding in B will increase, because the reinforcement frequency for B relative to all stimulus components has increased from .5 to 1.0. This analysis, however, cannot account for the increases in re- sponding during $\mathrm{S}-/ \mathrm{S}$ - components (i.e., time-outs in the present study). This is because the relative reinforcement frequency associated with these components was always 0 ; therefore, the observed increases in responding occurred in the absence of increased relative reinforcement frequency.

Additivity theory (Gamzu \& Schwartz, 1973; Schwartz \& Gamzu, 1977) also has troubles accounting for positive behavioral contrast in $S-/ S-$ responding. According to additivity theory, autopecks are elicited by the presentation of a stimulus when that stimulus is "differentially associated with a higher frequency of food presentations than obtains in the absence of that stimulus" (Gamzu \& Schwartz, 1973, p. 70). These elicited pecks, in addition to the usual pecks, result in positive behavioral contrast in an $\mathrm{S}+\mathrm{S}+$ component. This explanation cannot account for the appearance of positive behavioral contrast in an $S-/ S-$ component, because the $S-/ S-$ stimulus is never correlated with a higher frequency of reinforcement than that existing in the presence of the other stimuli.

In contrast with the relative reinforcement theory and the additivity theory, the behavioral competition theory (Hinson \& Staddon, 1978) can account for the appearance of positive behavioral contrast in $\mathrm{S}-/ \mathrm{S}-$ responding. This theory states that there exist two mutually exclusive classes of activity in the typical food-reinforcement operant situation. The first class (terminal responses) consists of activities that are directly related to food reinforcement, such as keypecking in the present experiment. The second class (interim responses) consists of all activities that are not directly related to food reinforcement, such as preening and wing-flapping. All of the organism's time is occupied by activities belonging to one or the other class, and these classes compete for available time. Thus, when one class of activity is somehow caused to decrease, the other class of activity will increase as it takes over the newly available time.

When two components ( $\mathrm{A}$ and $\mathrm{B}$ ) are associated with the same schedule of reinforcement, the degree of competition between interim and terminal responses is about the same in each component. This causes the rate of keypecking to be roughly equivalent in the two components. If reinforcement for keypecking in the presence of $A$ is subsequently eliminated, keypecking in $A$ will decrease and interim activity in A will increase. As a consequence of the increased interim activity in $\mathbf{A}$, competitive pressure for interim activity in B is reduced. Thus, interim activity in B decreases, which allows terminal activity in B to increase and fill up the newly available time. This, of course, translates into higher keypecking rates in $\mathrm{B}$-hence, the appearance of positive behavioral contrast. This approach can also account for positive behavioral contrast in $\mathrm{S}-/ \mathrm{S}$ - components, because the decrease in $\mathrm{S}+/ \mathrm{S}-$ responding may lead 
to reduced competition for $\mathrm{S}-/ \mathrm{S}-$ interim activity, as well as to reduced competition for $\mathrm{S}+/ \mathrm{S}+$ interim activity. Consequently, interim activity in both $S-/ S-$ and $\mathrm{S}+/ \mathrm{S}+$ components decreases, allowing terminal activity (e.g., keypecking) to increase.

In sum, the appearance of positive behavioral contrast in an S- /S - component is troublesome for the relative reinforcement and additivity theories, but is not troublesome for the behavioral competition theory. The present data, however, constitute only one observation of behavioral contrast in an $\mathrm{S}-/ \mathrm{S}-$ component, and therefore should not be regarded as firm evidence against the relative reinforcement and additivity theories. Nevertheless, these data do have important implications for these theories, and it is hoped that they will serve to stimulate further research into behavioral contrast in $\mathrm{S}-/ \mathrm{S}-$ components.

\section{REFERENCES}

Aronson, E., \& Linder, D. Gain and loss of esteem as determinants of interpersonal attractiveness. Journal of Experimental Social Psychology, 1965, 1, 156-171.

Blough, D. S. Steady state data and a quantitative model of operant generalization and discrimination. Journal of Experimental Psychology: Animal Behavior Processes, 1975, 104, 3-21.

Bonead, C. A., \& AxElrod, S. Work decrement and reminiscence in pigeon operant responding. Journal of Experimental Psychology, 1962, 64, 352-354.

Catania, A. C., \& Gill, C. A. Inhibition and behavioral contrast. Psychonomic Science, 1964, 1, 257-258.

Farthing, G. W. Behavioral contrast with multiple positive and negative stimuli on a continuum. Journal of the Experimental Analysis of Behavior, 1974, 22, 419-425.

Ferster, C. B., \& Skinnen, B. F. Schedules of reinforcement. New York: Appleton-Century-Crofts, 1957.

Gamzu, E., \& Schwartz, B. The maintenance of keypecking by stimulus-contingent and response-independent food presentation. Journal of the Experimental Analysis of Behavior, 1973, 19, 65-72.

Hinson, J. M., \& Malone, J. C. Local contrast and maintained generalization. Journal of the Experimental Analysis of Behavior, $1980,34,263-272$.

Hinson, J. M., \& Staddon, J. E. R. Behavioral competition: A mechanism for schedule interactions. Science, 1978, 202, 432-434.

Mackintosh, N. J. The psychology of animal learning. New York: Academic Press, 1974.

Mackintosh, N. J., Little, L., \& LoRd, J. Some determinants of behavioral contrast in pigeons and rats. Learning and Motivation, 1972, 3, 148-161.

Malone, J. C. Local contrast and Pavlovian induction. Journal of the Experimental Analysis of Behavior, 1976, 26, 425-440.

Matone, J. C., \& Rowe, D. W. Local contrast, local dimensional effects, and dimensional contrast. In M. L. Commons \& J. A. Nevin (Eds.), Quantitative studies of operant behavior: Discriminative properties of reinforcement schedules. Cambridge, Mass: Ballinger, in press.

Malone, J. C., \& Staddon, J. E. R. Contrast effects in maintained generalization gradients. Journal of the Experimental Analysis of Behavior, 1973, 19, 167-179.

Nevin, J. A., \& Shetrueworth, S. J. An analysis of contrast effects in multiple schedules. Journal of the Experimental Analysis of Behavior, 1966, 9, 305-315.

Pavlov, I. P. [Conditioned reflexes] (G. V. Anrep, trans.). New York: Dover, 1927.

REYNolds, G. S. An analysis of interactions in a multiple schedule.
Journal of the Experimental Analysis of Behavior, 1961, 4, 107-117. (a)

REYNolds, G. S. Behavior contrast. Journal of the Experimental Analysis of Behavior, 1961, 4, 57-71. (b)

REYNOLDS, G. S. Contrast, generalization, and the process of discrimination. Journal of the Experimental Analysis of Behavior, 1961, 4, 289-294. (c)

Reynolds, G. S., \& Catania, A. C. Behavioral contrast with fixed-interval and low-rate reinforcement. Journal of the Experimental Analysis of Behavior, 1961, 4, 387-391.

RILling, M. Stimulus control and inhibitory processes. In W. K. Honig \& J. E. R. Staddon (Eds.), Handbook of operant behavior. Englewood Cliffs, N.J: Prentice-Hall, 1977.

Schwartz, B., \& Gamzu, E. Pavlovian control of operant behavior: An analysis of autoshaping and its implications for operant conditioning. In W. K. Honig \& J. E. R. Staddon (Eds.), Handbook of operant behavior. Englewood Cliffs, N.J: PrenticeHall, 1977.

Skinner, B. F. The behavior of organisms. New York: AppletonCentury, 1938.

Spence, K. W. The differential response in animals to stimuli varying within a single dimension. Psychological Review, 1937, 44, 430-444.

Terrace, H. S. Discrimination learning with and without errors. Journal of the Experimental Analysis of Behavior, 1963, 6, 1-27.

\section{NOTES}

1. Local contrast appears to be the same phenomenon that Pavlov (1927) originally described and called "induction." However, Skinner's (1938) definition of induction is the opposite of Pavlov's. In this paper, it is Skinner's definition, not Pavlov's, that is followed. Local contrast has also been called "transient contrast"' (Nevin \& Shettleworth, 1966).

2. The parameters used in generating the best fit of the actual data were:

(1) Thirty-seven stimulus elements were activated at one time or another in the experiment. Each stimulus activated a total of 13 elements; these were the element that corresponded with the stimulus's center and six adjacent elements in each direction from the center. Along the stimulus element continuum, the center of 0 fell at Element 7,15 deg had its center at Element 11,30 deg had its center at Element 15, $45 \mathrm{deg}$ had its center at Element 19,60 deg had its center at Element 23, 75 deg had its center at Element 27, and $90 \mathrm{deg}$ had its center at Element 31.

(2) The generalization weighting function $\left(\gamma_{s i}\right)$ had the following values: $\gamma_{\mathrm{s}}=.4, \gamma_{\mathrm{s} \pm 1}=.35, \gamma_{\mathrm{s} \pm 2}=.24, \gamma_{\mathrm{s} \pm 3}=.13, \gamma_{\mathrm{s} \pm 4}=.054$, $\gamma_{\mathrm{s} \pm 5}=.018$, and $\gamma_{\mathrm{s} \pm 6}=.0044$.

(3) $\beta \uparrow=.2$ and $\beta \downarrow=.025$.

(4) The initial strength of each element $\left(v_{i}\right)=.4$.

(5) $\lambda_{s_{+}}=1$, and $\lambda_{s_{-}}=0$.

3. Aronson and Linder's (1965) research, which could perhaps be considered analogous to the present research, may lend support to this hypothesis. In their study, subjects reacted less positively (in the form of less liking) to a confederate who first said positive, then negative, things (i.e., served as an $\mathrm{S}+/ \mathrm{S}-$ ) about the subject than they did to any other type of confederate. This was similar to the present study, which also showed that subjects reacted less positively (in the form of less keypecking) to an $\mathrm{S}+/ \mathrm{S}-$ than to any other stimulus. Aronson and Linder also found that subjects reacted with greater liking for a confederate who first said negative, then positive, things (i.e., served as an $\mathrm{S}-/ \mathrm{S}+$ ) about the subject than they did for any other confederate, including one who always said positive things (i.e., served as an $\mathrm{S}+/ \mathrm{S}+$ ) about the subject. If one allows the analogy between Aronson and Linder's study and the present type of study, then, on the basis of their data, one would expect more frequent responding in $\mathrm{S}-/ \mathrm{S}+$ components than in $\mathrm{S}+/ \mathrm{S}+$ components.

(Received for publication April 20, 1980; revision accepted August 14, 1980.) 